ISSN 1518-3483

Licenciado sob uma Licença Creative Commons

\title{
Condições de avaliação e internacionalidade da pesquisa em ciências sociais hoje $\mathrm{e}^{1,2}$
}

\author{
Michel Messu *
}

Université de Nantes et PHILéPOL Université Paris Descartes, Nantes, France

\section{Introdução}

Em vinte anos, talvez um pouco mais, as condições de pesquisa em ciências sociais mudaram profundamente. Nos dias atuais, exige-se não apenas produzir resultados mais regulares, mas fazer isso em condições de reconhecimento, enquadrando-se em uma nova escala: o reconhecimento internacional.

1 Título original no francês "La recherche en sciences sociales aujourd'hui", traduzido por Cristina Albuquerque (Universidade de Coimbra, Portugal). Sendo assim, no presente documento foi preservada a grafia do país de origem da tradutora. Conferência proferida na Aula Magna do Programa de Pós-Graduação em Educação da Pontifícia Universidade Católica do Paraná (PPGEPUCPR), no dia 14 de maio de 2014.

2 Texto publicado em francês no v. 14, n. 43, da Revista Diálogo Educacional, p. 941-953, set./dez. 2014.

* MS: Doutor, e-mail: michel.messu@univ-nantes.fr 
Por um longo tempo, de fato, a pesquisa em ciências sociais foi concebida, realizada e avaliada em nível nacional, com financiamento local e nacional. Suas avaliações eram feitas pelos nossos "pares", isto é, nossos colegas de universidades nacionais, os mesmos que costumávamos encontrar em nossas universidades, nos encontros científicos e nos conselhos editoriais de revistas nas quais publicávamos. Em outras palavras, estávamos entre nós, conheciamo-nos bem, falávamos a mesma língua, compartilhando ou não os mesmos objetos de pesquisa ou as mesmas abordagens. Tínhamos os mesmos quadros referenciais teóricos e os mesmos dados empíricos. Em suma, a concorrência e a emulação apresentavam-se internamente entre as fronteiras de um país (ou de alguns países onde a língua comum nos une, por exemplo, entre França, Bélgica, Suíça e Quebec, no Canadá).

Daí o surgimento de tradições, Escolas, especificidades enraizadas em lugares bem definidos, que podem ser caracterizadas geográfica e culturalmente. Assim, a Escola Alemã, a Escola Francesa, a Escola de Chicago, em sociologia, a tradição anglo-americana versus a tradição francófona em antropologia etc. são casos bem conhecidos que identificam esse fenômeno. Era sobre essa base que se desenvolviam as ciências sociais nacionais.

Mas isso tudo mudou.

\section{As grandes mudanças na pesquisa em ciências sociais}

O que mudou desde logo - e penso que isso é verdadeiro quer no Brasil, quer na Europa ou na América do Norte e no resto do mundo foi a internacionalização da pesquisa. Esta se internacionalizou de muitas maneiras, nomeadamente, através: do desenvolvimento de comparações internacionais, da organização de redes internacionais de investigação, do financiamento internacional e das publicações on-line - os "periódicos eletrônicos". 


\section{Internacionalização por via de estudos comparativos}

Cada vez mais as pesquisas se orientam para a comparação de situações em diferentes países. O que foi excepcional na década de 1970 tornou-se regra na atualidade. O desemprego na França, por exemplo, parece não ser possível de se analisar se não o relacionando com o que ocorre na Espanha, em Portugal, na Alemanha, em todos os países da Europa, do mundo ocidental. Sobre o plano econômico, o PIB (GDP) e suas várias versões (PIB PPA: paridade de poder aquisitivo etc.) tornou-se um critério-chave para avaliar qualquer situação, nacional, regional ou local. Avaliar a "pobreza" no Brasil é compará-la com o resto da América Latina ou do mundo.

A mesma coisa ocorre em relação aos sistemas de proteção social, de educação, de saúde, do meio ambiente etc. Em outras palavras, a nossa visão das questões sociais é construída primeiramente tomando como referência a forma que elas assumem no resto do mundo. Elas se apresentam, portanto, menos como questões "em si", cujo tratamento poderia legitimamente ocorrer no âmbito nacional, o que circunscreveria a sua relevância, mas muito mais como questões relativas, questões de medida de um fenómeno macrossocial no qual diversos parâmetros se encontram renovados.

Existem, é claro, boas razões epistemológicas e metodológicas para assim se proceder. Na verdade, muitos fenómenos sociais se apresentam doravante como efeitos de fenômenos globais ou como singularidades nacionais dos problemas colocados a uma outra escala coletiva, ou mesmo como respostas cuja modalidade deôntica é a da possibilidade. Portanto, a comparação entre situações inter-nacionais se impõe como uma condição de compreensão do fenômeno estudado e como método de apreensão relativa desse mesmo fenómeno. Assim dizendo, a abordagem comparativa evidencia muitos problemas de método. Portanto, compara-se o que exatamente? Sabemos bem que o ceteris paribus, ou seja, "tudo o mais constante", é raramente assegurado em ciências sociais. Por outro lado, a comparação se legitima como uma nova maneira de dar sentido aos nossos objetos de pesquisa. 


\section{Internacionalização pela organização de redes de pesquisa}

O que mudou também, é que a organização prática da pesquisa é cada vez mais realizada no âmbito de redes internacionais. O réseautage, como dizem os quebequenses, o networking, como dizem os anglófonos, a criação de redes de investigadores, dos seus objetos de pesquisa, dos seus resultados, mas também das suas questões teóricas, metodológicas, dos seus dados empíricos, de suas informações bibliográficas etc., tudo isto tornou-se uma atividade cotidiana do pesquisador. A pesquisa está longe de ser um exercício solitário. Ela exige comunicação e intercâmbio com inúmeros pesquisadores ao redor do mundo, e não apenas com os de sua equipe, do seu centro de pesquisas.

Eu sou, por exemplo, um membro de uma rede, no Linkedin, de discussão intitulada "Research, Methodology and Statistics in the Social Sciences" e não há dia em que não se lançem vários pedidos e discussões sobre um problema colocado por um ou outro pesquisador entre os membros da rede. São pesquisadores localizados nos Estados Unidos, na China, na África, na Índia e no Brasil, pertencentes a diferentes universidades e outras organizações de pesquisa; podem ser jovens pesquisadores ou professores titulares com vasta experiência, mas compartilham um problema comum e o discutem diretamente.

Isto significa dizer que algumas pesquisas hoje escapam das estruturas hierárquicas da organização local e nacional. Esta pesquisa se realiza também através da internet, em comum acordo entre pesquisadores diferentes, o que pode ser entendido como um ganho de liberdade do investigador.

Mas para além destas práticas individuais de trabalho em rede, está surgindo, cada vez mais, um constrangimento institucional de obrigação de colaboração internacional. Nossas instituições nacionais exigem dos seus pesquisadores a multiplicação de atividades colaborativas com equipes de outros países e de outros centros de pesquisa. Embora as atividades pesquisa de hoje se realizem entre membros de centros de pesquisas implantados em vários países, estas se realizam por vezes para efeito de comparação, mas nem sempre. Isso permite que as questões comuns 
sejam elaboradas e testadas, desta forma, com resultados que suplantam as fronteiras nacionais e se difundem de forma mais ampla. Assim, existem problemáticas compartilhadas, nomeadamente em termos de desenvolvimento econômico e social, que são definidas por organizações internacionais (FMI, Banco Mundial, Unesco etc.), e que se tornam o próprio quadro da pesquisa no qual as equipas locais se vão inscrever. Estas coletam os dados locais os comparando com os de outras equipes e uniformizando, assim, a abordagem da problemática. O Conselho Latinoamericano de Ciências Sociais (CLACSO), bem conhecido aqui no Brasil, também tem esse papel. Para nós franceses, são os programas europeus que desempenham este papel.

É claro que ainda existem instâncias nacionais ou locais, mas estas, cada vez mais, exigem que seus projetos de pesquisa sejam inseridos no âmbito de programas internacionais. Estas instâncias apoiam muitas vezes as primeiras iniciativas dos centros de pesquisa, de modo que estes integrem as redes internacionais.

\section{Internacionalização pelos financiamentos}

Na maioria das vezes, as motivações de tais políticas são financeiras. Na verdade, os recursos alocados para a pesquisa estão de agora em diante concentrados em poucos lugares: agências nacionais ou internacionais, organizações supraestatais ou ONGs poderosas, gerenciando, portanto, fundos públicos e/ou privados. Consequentemente, as instâncias locais, especialmente as universitárias, tornam-se menos presentes, em termos de financiamento, em programas importantes de investigação, ainda que continuando a consagrar meios próprios mas à sua escala.

Esta dependência em relação às fontes de financiamento internacional tem evidentemente efeitos em termos de resultados e reconhecimento dos investigadores. Isso muitas vezes torna-se um critério para avaliar os próprios pesquisadores. Muitas vezes, em propostas ou projetos de investigação, é mencionado (ou deve-se mencionar) quanto "pesa" em 
dólares, em euros, ou em outra moeda, determinado pesquisador, traduzindo-se como prova de seu reconhecimento e credibilidade. Isso facilita a obtenção de um novo crédito e reforça a tendência ao que alguns chamam de imposição da problemática. De qualquer maneira, isto tende a reforçar os quadros de investigação predefinidos em instâncias internacionalizadas.

\section{Internacionalização pela publicação on-line, especialmente as "revistas eletrônicas"}

Outro fator torna a pesquisa cada vez mais independente do quadro nacional: a publicação dos resultados. Durante muito tempo era nas revistas nacionais, por vezes muito antigas (como, no caso da França, revistas fundadas por Durkheim, Gurvitch ou patrocinadas por grandes nomes como Aron, Lévi-Strauss, Touraine, Bourdieu... - isto para a sociologia), que a pesquisa era publicada e divulgava-se os seus resultados a um público essencialmente nacional. O reconhecimento se fazia, portanto, por meio destas publicações nacionais, o que se traduzia pela utilização de referências bibliografias essencialmente nacionais. A título de curiosidade, faziam-se consultas a revistas estrangeiras, mas estas não tinham o caráter de essencialidade como as revistas nacionais.

Mas era antes de tudo pelos livros que se fazia a divulgação e o reconhecimento da investigação. Em geral, quando a idade e a experiência ajudavam, uma proposta teórica original, uma análise inédita ou resultados incontestavelmente novos, ela poderia ser proposta a uma editora com carimbo "universitária". O máximo do reconhecimento era a tradução do livro em outros idiomas além daquele que foi escrito. Assim acessava-se então à categoria dos happy few da pesquisa nacional.

Doravante, o reconhecimento se faz pela publicação de artigos, mas não em qualquer revista. A publicação, especialmente se o pesquisador é jovem, deve receber imediatamente o reconhecimento internacional e deve ser capaz de se apresentar em algumas "grandes revistas". Nossas instâncias acadêmicas promovem também, às vezes, rankings dessas 
revistas. As primeiras são geralmente anglo-americanas. Quase todas são, seja exclusivamente, seja complementarmente, on-line, ou seja, são "revistas eletrônicas" acessíveis por meio da internet, por vezes com custos de acesso, outras vezes com acesso gratuito.

Apresenta-se desde logo uma espécie de mercado de revistas, dado que algumas estão lá para ganhar dinheiro, e para isso solicitam diariamente aos pesquisadores por e-mail, porque sabem da sua necessidade imperativa de publicar. Existe, assim, particularmente para jovens investigadores, uma espécie de mercadorização de artigos de pesquisa. Isto merece ser analisado com mais profundidade. Mas outras revistas, estritamente acadêmicas, tendem a reforçar os seus critérios de aceitação, uma vez que recebem cada vez mais propostas de artigos. Frequentemente adotam políticas, seja de maior especialização, seja, ao contrário, de maior diversificação.

Em suma, com a pressão institucional para a publicação de artigos sendo mais forte, os pesquisadores são condicionados a publicarem amplamente em "revistas eletrônicas".

\section{Os benefícios dessas mudanças}

Múltiplas consequências podem ser associadas a estas mudanças. Algumas são sobretudo benéficas para a pesquisa. Examinarei aqui apenas as três que considero mais importantes e mais ou menos vantajosas:

- Redução dos confinamentos teóricos. Referindo-me à situação francesa, sem dúvida, foi a internacionalização da investigação que permitiu superar os conflitos de Escolas que marcaram e paralisaram um pouco as pesquisas a partir de 1970. Sem entrar em detalhes, a situação da pesquisa, particularmente em sociologia, mas isso também é verdadeiro em economia e em outras disciplinas, congelou as querelas aparentemente teóricas, mas mais fundamentalmente de opção ideológica. Querelas "paroquiais", mas às quais os pesquisadores deveriam se submeter 
para obter qualquer tipo de reconhecimento. Ser filiado a uma corrente de pensamento, esta era a regra, implícita, mas fortemente presente e obrigatória. Portanto, com consequências em termos de financiamento, de postos de investigadores, de publicações, entre outras.

O desenvolvimento da internacionalização da investigação nos permitiu, pois, superar essas barreiras nacionais.

- Em segundo lugar, reduziu-se o "clientelismo" local. Ou seja, esses tipos de benefícios adquiridos ao longo do tempo que fizeram com que alguns centros de pesquisa, certas equipes, disfrutassem de uma vantagem decorrente do interconhecimento dos pesquisadores com os decisores locais. A suposta competição entre as equipes era, portanto, muitas vezes distorcida por este sistema de convivência.

A internacionalização da investigação colocou tudo isto em questão.

- Finalmente, a internacionalização teve muitos efeitos benéficos para a divulgação dos resultados da investigação. Mais uma vez, dependendo menos das redes locais ou redes constituídas ao redor de Escolas Teóricas, a difusão de resultados pôde ser feita em uma escala muito maior. Ao abordar urbi et orbi, o pesquisador pode ser reconhecido para além do círculo em que ele está localizado. É claro que com limites, e às vezes com obstáculos. E aqui é necessário pensar, em particular, na língua através da qual predominantemente se faz esta transmissão. Mas esta questão prefiro tratar com mais detalhes na próxima seção, sobre os inconvenientes da internacionalização da investigação nas ciências sociais.

\section{As desvantagens dessas mudanças}

Antes de tratar sobre a questão da língua, eu gostaria de sublinhar uma das consequências mais importantes, na minha opinião, das mudanças 
na forma de conceber e realizar pesquisas. Refiro-me à tendência de padronização da pesquisa. Esta padronização ocorre de diferentes maneiras:

Pela imposição de problemáticas, tendo origem, frequentemente, em órgãos financiadores da pesquisa, como já foi mencionado, ainda que tal imposição não se faça de forma direta e imperativa. Exceto quando se professam opções teóricas que não derivam necessariamente da disciplina praticada. Mas dentro do corpo teórico reconhecido das disciplinas das ciências sociais, a variedade de abordagens é geralmente aceita, mesmo porque os comitês de avaliação de projetos são compostos por representantes dessas disciplinas, podendo haver entre eles diferenças de opções teóricas. A padronização das questões de investigação não se faz, portanto, de maneira tão autoritária pela imposição de opções teóricas dos órgãos que controlam a pesquisa.

Mais contundente no sentido da padronização, parece ser a imposição de abordagens metodológicas e deontológicas. É muitas vezes pelo método a ser adotado que se realiza a imposição da problemática. As ciências sociais admitem, em princípio, uma grande variedade de métodos e procedimentos de investigação. E o debate sobre o método comporta frequentemente um desafio de compreensão e de análise do objeto da pesquisa. A construção dos dados, das categorias de análise, dos procedimentos de análise de dados, dos conceitos utilizados para formular as conclusões, tudo isto interfere plenamente, como se sabe, na produção dos resultados de pesquisa. No entanto, limitar os dados a um tipo (a estatística nacional, por exemplo), orientar os procedimentos de investigação na direção de um mesma abordagem (como tipo de entrevista, configuração de quotas etc.), realizar uma análise padrão desses dados (sejam estes quantitativos ou qualitativos), tudo isto tende a produzir modelos de pesquisa. Ou seja, procedimentos de pesquisa que obedecem, antes de tudo, a um a priori da construção e sobre os quais devemos sempre discutir a pertinência. Questões prévias à construção do objeto, de conceitos, de métodos etc., que fazem logicamente parte do desenvolvimento da pesquisa e deveriam permanecer como uma prerrogativa do pesquisador. Aceitar que isso se faça a montante da pesquisa é promover e reforçar a 
padronização da investigação. Com isto constata-se ex-post uma espécie de "formatação" das publicações.

Mais incidioso, parece-me, mas caminhando na mesma direção da padronização, é o chamado constrangimento deontológico, promovido pelos diversos Comitês de Ética que coexistem com os organismos de promoção de investigação. Um tal constrangimento, pelo menos como o proclamamos, tem como objetivo proteger as pessoas que são os sujeitos humanos objeto de pesquisa, ou seja, garantindo-lhes "direitos" para não serem maltratados pelos pesquisadores. A intenção é louvável, não se discute. Mas frequentemente as "declarações deontológicas" são aplicadas para proteger as instituições contra processos judiciais que poderiam ser instituídos pelos "sujeitos" descontentes com o comportamento dos investigadores ou com os resultados da investigação.

Em acréscimo, essas "declarações deontológicas" tendem a excluir certos procedimentos ou certos métodos considerados demasiados intrusivos sobre os "sujeitos" e, portanto, por isso, a interditar um certo tipo de pesquisa. Foi o sociólogo Howard Becker que declarou que, se tivesse de seguir as "declarações deontológicas" impostas hoje pelas universidades americanas, ele nunca poderia ter escrito seus livros que todo mundo reconhece como grandes obras da disciplina sociológica. A partir deste ponto de vista, a imposição das "declarações deontológicas" pelas organizações que encomendam a pesquisa produz um real efeito de padronização, de uniformização e de empobrecimento desta. É um efeito altamente negativo das mudanças que estamos analisando.

Agora analisaremos a questão da língua; a língua na qual são cada vez mais comunicados os resultados da pesquisa. Trata-se, bem entendido, da utilização predominante do inglês. As grandes revistas são todas, ou quase todas, de língua inglesa, e se queremos nos informar rapidamente sobre notícias da nossa disciplina, é melhor praticar o inglês. Mas antes de falar sobre o imperialismo do idioma inglês, gostaria de precisar duas coisas.

A primeira é que este inglês é a língua utilizada nas trocas convencionais em cada disciplina. Trata-se de um inglês restrito, por vezes, 
muito técnico e que serve em primeiro lugar para falar com uma linguagem comum entre os pesquisadores praticantes de diferentes idiomas na vida cotidiana. Além disso, isto faz muitas vezes sorrir os britânicos nativos, porque este inglês lhes parece bastante incorreto. Até mesmo inventou-se uma palavra para dizer e designar este inglês praticado por pessoas não inglesas para enunciar certas coisas referentes às suas próprias atividades: falamos de globish, do "inglês global". Muitas vezes, porém, esta é a língua das instâncias políticas internacionais que contamina a comunidade de pesquisa.

Apesar de tudo, é com este inglês que as trocas se realizam em escala mundial, entre pesquisadores de países muito diferentes, os quais, sem ele, jamais trocariam informações. Quem, na França ou no Brasil, teria conhecimento do trabalho de um investigador do Paquistão, da Indonésia, da África do Sul, da Letónia etc., sem a utilização desta linguagem comum que é o inglês? Trata-se de uma língua comum, uma vez que, de fato, é a mais praticada no mundo para este tipo de intercâmbio. O inglês é, portanto, o meio de comunicação entre os pesquisadores. Por outro lado, esta não deve ser uma linguagem universal com a qual se realize toda pesquisa.

De fato, dominar mais ou menos corretamente o inglês não é o suficiente para fazer numerosas investigações. Particularmente nas ciências sociais, em que o "material" da pesquisa é um "material humano", definido histórica e culturalmente, a prática da língua nacional é, portanto, muitas vezes indispensável. Viu-se isso muito claramente na chamada Primavera Árabe, quando eram os pesquisadores árabes que poderiam melhor explicar o que estava acontecendo. Aquelas pessoas que dominavam apenas o inglês muitas vezes permaneceram na superfície das coisas. Outro exemplo: os atuais pesquisadores que se dedicam ao estudo sobre a China não conseguem entender grande coisa, além do discurso das autoridades, se não falarem um pouco de mandarim ou de outros dialetos chineses. Isto significa que a pesquisa não pode ser realizada utilizando-se uma única linguagem, mesmo que esta seja comum para os pesquisadores. A pesquisa exige também que se tome em consideração a linguagem 
dos "sujeitos" que são objetos de investigação. Isto é, não se deve considerar apenas a linguagem utilizada pelos pesquisadores entre eles.

Mas é preciso considerar que deve haver uma linguagem comum que sirva de instrumento de troca entre pesquisadores. Então, esta é o inglês! Devo lhes dizer, isto provoca muita tristeza aos franceses, especialmente àquelas pessoas que pensavam ser os únicos capazes, a partir do Século das Luzes, de "iluminar" o mundo.

\section{Um apelo por uma pesquisa multinacional não padronizada}

Para finalizar, eu gostaria de fazer uma proposta relacionada ao desenvolvimento da pesquisa em ciências sociais. Gostaria de pleitear pela manutenção de uma pesquisa multinacional não standard. As mudanças que constatámos comportam, como disse, vantagens e desvantagens. Adotemos as vantagens e combatamos os inconvenientes:

- Preservemos o poder de nos dirigirmos diretamente aos outros pesquisadores para além das barreiras institucionais, Escolas de pensamento, circuitos fechados - locais ou nacionais - de financiamento. Assim a pesquisa poderia ser menos fundada sobre relações pessoais, conivências institucionais ou de circuitos fechados de reconhecimento, abrindo possibilidade a uma pesquisa mais marcada pelo "espírito científico", em qualquer caso, mais facilmente heurística, mais centrada na compreensão do objeto de estudo.

- Reforcemos, do mesmo modo, o poder de comunicar amplamente nossos resultados, para além das divisões de Escolas, hábitos ou preferências teórico-ideológicas de revistas e de editores. As revistas e os editores deverão adaptar-se. O ciberespaço permite-o, o que reclama um aumento da vigilância por parte do pesquisador. 
- Mas reservemos também o poder de conduzir, de acordo com procedimentos reconhecidos pelas disciplinas, a pesquisa que nós queremos, e não apenas aquela que convém às agências nacionais ou internacionais que a financiam. Guardemos o poder de dizer "não" às imposições de métodos e abordagens, quando elas parecem bloquear a descoberta científica e a inovação. Devemos afirmar que a deontologia é um assunto dos pesquisadores e não das instituições gerenciadoras de pesquisa.

- Proclamemos, enfim, a nossa capacidade de encontrar, inventar, produzir resultados que podem renovar o conhecimento. Continuemos, portanto, fazendo o nosso trabalho de pesquisador, no sentido pleno do termo, com seus riscos, desconfortos, incertezas, mesmo que devamos fazer no âmbito das novas condições de pesquisa internacionalizada, sem, porém, tornarmo-nos funcionários de uma pesquisa global, formatada, muitas vezes sem imaginação e às vezes altamente ideologizada.

- Aproveitemos, portanto, a abertura mundial da pesquisa para torná-la mais colaborativa e imaginativa. Isto não exclui o rigor, pelo contrário, uma vez que obedecerá a uma vigilância coletiva muito mais ampla. Abandonemos os nossos grilhões locais ou nacionais, sem, no entanto, deixarmo-nos levar na direção dos grilhões da estandardização e da uniformização tendencialmente defendidos pelas instâncias internacionais.

Prosseguir uma pesquisa não estandardizada e multinacionalizada parece-me ser hoje uma garantia de desenvolvimento e de sucesso da pesquisa em ciências sociais.

Recebido: 10/10/2015

Received: 10/10/2015

Aprovado: $15 / 02 / 2016$

Approved: 02/15/2016 
